\title{
The epidemic of SIDS in Norway 1967-93: changing effects of risk factors
}

\author{
Anne Kjersti Daltveit, Nina Øyen, Rolv Skjærven, Lorentz M Irgens
}

Medical Birth Registry of Norway, University of Bergen, Norway A K Daltveit

L M Irgens

Division of Preventive Medicine, Department of Public Health and Primary Health Care, University of Bergen, Norway

$\mathrm{N} \emptyset$ Øen

Division of Medical Statistics, Department of Public Health and Primary Health Care, University of Bergen, Norway

R Skjærven

Correspondence to: Dr Anne Kjersti Daltveit, Medical Birth Registry of Norway, University of Bergen, Armauer Hansen Building, Haukeland Hospital, N-5021 Bergen, Norway.

Accepted 18 March 1997

\begin{abstract}
Time trends on the association of maternal age, birth order, and marital status with the risk of sudden infant death syndrome (SIDS) and non-SIDS deaths in Norway were analysed: 2356 postperinatal SIDS deaths and 4069 postperinatal nonSIDS deaths were ascertained during 1967-93. The SIDS incidence was 1.25 per 1000 in 1967 , reached a peak of 2.69 in 1988 , and fell to 1.22 in 1990 after the initiation of an intervention programme to avoid prone sleeping. In the entire period, young maternal age, high birth order, and unmarried motherhood were associated with SIDS. The adverse effects of young maternal age and high birth order increased continuously with time. From 1967-71 to $1990-93$, the relative risk for maternal age $<20$ years $v$ maternal age 25-29 changed from 2.5 (95\% confidence interval 2.0 to 3.2$)$ to 7.0 (95\% CI 4.2 to 11.9$)$ ( $<<0.0001)$, and for birth order $4+v$ birth order 1 from 3.2 (95\% CI 2.5 to $4.2)$ to $14.4(95 \%$ CI 8.3 to 24.9$)$ $(p<0.0001)$. Effects on non-SIDS deaths were far weaker and no secular trends were observed. The strong association of young maternal age, high birth order, and marital status in SIDS, but not in nonSIDS, provides evidence that SIDS is an epidemiological entity. The increasing effects of young maternal age and high birth order, which continued after the sudden drop in the SIDS rate in 1990, suggest that further efforts to prevent SIDS should be aimed particularly at identifying causal mechanisms in high risk groups.

(Arch Dis Child 1997;77:23-27)
\end{abstract}

Keywords: SIDS; maternal age; birth order; Norway

Young maternal age, high birth order, and unmarried marital status have repeatedly been shown to increase the risk for sudden infant death syndrome (SIDS). ${ }^{1-4}$ The strength of these effects and the consistent findings in different populations suggest that these factors are important in the aetiology of SIDS.

Since the early 1980s, SIDS in Norway has been monitored by a comprehensive epidemiological surveillance system. ${ }^{5}$ This system, which covers all postperinatal deaths from 1967 onwards, provides a database for epidemiological studies. Relatively large fluctuations in the annual SIDS rate have been observed, with an underlying increase during the $1980 \mathrm{~s}^{5}$ From 1989 to 1990 , there was a $50 \%$ reduction in the rate, followed by further declining rates in subsequent years. ${ }^{6}$ A campaign to avoid prone sleeping was launched in January $1990 .^{7}$ The sudden drop in the SIDS rate was a turning point and can probably be attributed to a fall in the prevalence of prone sleeping from $49 \%$ in 1989 to $27 \%$ in $1990 .{ }^{6}$ Similar falls in the SIDS rate in other countries have also been explained by changes in sleeping position. ${ }^{8-12}$

Our aim was to establish the effects of maternal age, birth order, and marital status during 1967-93, and to assess whether these effects were influenced by the changes in mortality.

\section{Methods}

The study was based on data from the Medical Birth Registry of Norway, established in 1967 and comprising all live births as well as stillbirths after 16 weeks of gestation. The records are routinely linked with computerised death certificates from the Central Bureau of Statistics. The underlying cause of death and up to three contributing causes of death are coded according to the International Classification of Diseases (ICD) eighth revision (1967-85) and ninth revision (from 1986). A procedure for identifying SIDS cases from the birth records linked with death certificates has been implemented, and a database established of all infant deaths in Norway from 1967 onwards. ${ }^{5}$ Our classification of all postperinatal deaths into SIDS deaths and non-SIDS deaths is based on this database.

The population at risk was all babies born between 1967 and 1993 who survived the first week of life (1 540331 births). Mortality was calculated as the number of deaths per 1000 first week survivors. The ratio of mortality rates (rate ratio) was the effect measure. SIDS rates were adjusted for maternal age and birth order, marital status, and birth weight by logistic regression, with odds ratios and corresponding $95 \%$ confidence intervals. ${ }^{13}$ Since mortality was low, the odds ratios were interpreted as rate ratios. In the logistic regression analyses, the independent variables were represented by indicator variables to avoid assumptions of linear associations. We classified maternal age into five categories ( $\leqslant 19,20-24,25-29$, $30-34, \geqslant 35$ years), birth order into four $(1,2$, $3,4+)$, year of birth into six periods (1967-71, 1972-76, 1977-81, 1982-85, 1986-89, 199093), and birth weight into four categories (<2500, 2500-2999, 3000-3499, and $\geqslant 3500$ g). Marital status was categorised into married/ 


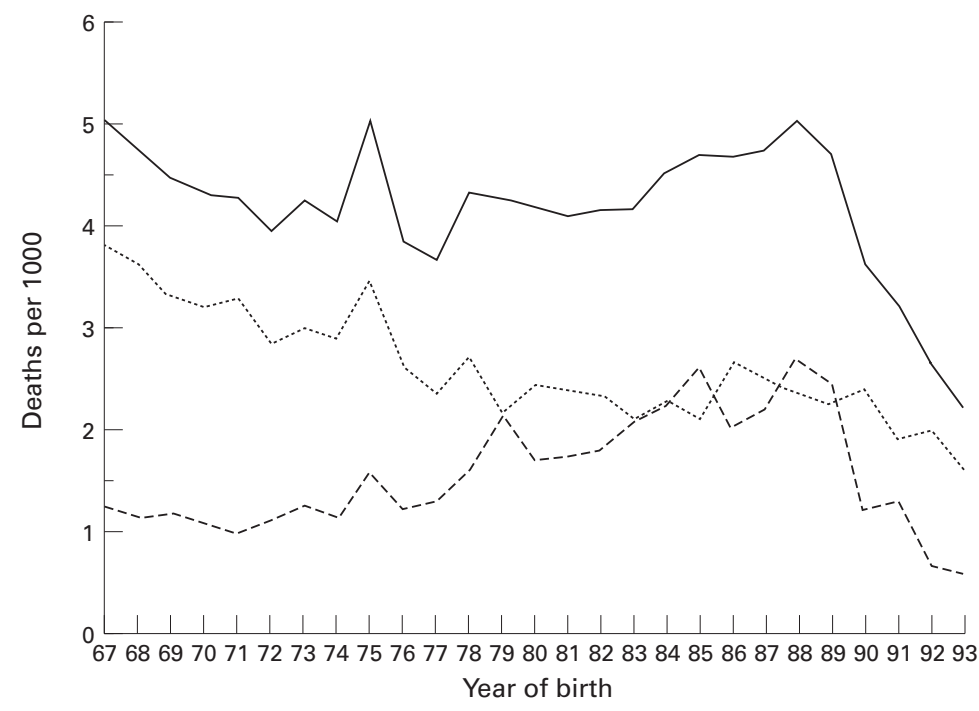

------ SIDS …............ non-SIDS Total

Figure 1 Rates of postperinatal SIDS deaths and non-SIDS deaths in Norway 1967-93, by year of birth.

Table 1 Proportions (per 100) of births to young (\$19), multiparous (4+) and unmarried mothers by period of birth. First week survivors, Norway 1967-93

\begin{tabular}{lcccccc}
\hline \multicolumn{7}{l}{ Period of birth } \\
\cline { 2 - 7 } & $1967-71$ & $1972-76$ & $1977-81$ & $1982-85$ & $1986-89$ & $1990-93$ \\
\hline Maternal age $\leqslant 19$ & 9.7 & 10.7 & 8.1 & 6.2 & 5.2 & 4.0 \\
Birth order 4+ & 13.1 & 8.4 & 6.0 & 5.9 & 5.4 & 6.0 \\
Unmarried mothers & & & & & & \\
$\quad$ All & 6.4 & 10.0 & 13.9 & 21.2 & 32.4 & 41.4 \\
$\quad$ Cohabiting & & & & & 21.9 & 32.0 \\
$\quad$ Single & & & & & 10.5 & 9.4 \\
\hline
\end{tabular}

Table 2 Crude rates of SIDS and non-SIDS deaths according to maternal age, birth order and marital status, by period of birth. Postperinatal deaths, Norway 1967-93

\begin{tabular}{|c|c|c|c|c|c|c|}
\hline & \multicolumn{6}{|c|}{ Period of birth } \\
\hline & $1967-71$ & $1972-76$ & $1977-81$ & $1982-85$ & $1986-89$ & $1990-93$ \\
\hline \multicolumn{7}{|l|}{ SIDS } \\
\hline \multicolumn{7}{|c|}{ Maternal age (years) } \\
\hline$\leqslant 19$ & 1.47 & 1.85 & 2.94 & 4.22 & 5.54 & 2.74 \\
\hline $20-24$ & 1.39 & 1.41 & 2.06 & 2.90 & 3.31 & 1.43 \\
\hline $25-29$ & 1.00 & 1.13 & 1.40 & 1.60 & 1.89 & 0.85 \\
\hline $30-34$ & 0.72 & 0.96 & 1.23 & 1.80 & 1.61 & 0.50 \\
\hline$\geqslant 35$ & 0.69 & 0.53 & 1.08 & 1.39 & 1.23 & 0.58 \\
\hline \multicolumn{7}{|l|}{ Birth order } \\
\hline 1 & 0.74 & 1.04 & 1.32 & 1.61 & 1.63 & 0.61 \\
\hline 2 & 1.47 & 1.40 & 2.06 & 2.45 & 2.77 & 1.02 \\
\hline 3 & 1.41 & 1.50 & 1.82 & 2.94 & 2.91 & 1.31 \\
\hline $4+$ & 1.14 & 1.18 & 1.77 & 2.26 & 3.83 & 1.81 \\
\hline \multicolumn{7}{|l|}{ Marital status } \\
\hline Married & 1.06 & 1.20 & 1.57 & 2.02 & 2.13 & 0.80 \\
\hline Unmarried & 2.22 & 1.73 & 2.48 & 2.70 & 2.78 & 1.17 \\
\hline Cohabiting & - & - & - & - & 2.14 & 0.83 \\
\hline Single & - & - & - & - & 3.90 & 2.32 \\
\hline \multicolumn{7}{|l|}{ Non-SIDS } \\
\hline \multicolumn{7}{|c|}{ Maternal age (years) } \\
\hline$\leqslant 19$ & 4.00 & 3.64 & 3.37 & 2.79 & 2.68 & 2.74 \\
\hline $20-24$ & 3.28 & 2.82 & 2.53 & 2.61 & 2.57 & 2.04 \\
\hline $25-29$ & 3.05 & 2.65 & 2.18 & 2.03 & 2.14 & 1.79 \\
\hline $30-34$ & 3.48 & 2.94 & 2.11 & 1.90 & 2.46 & 2.18 \\
\hline$\geqslant 35$ & 4.75 & 4.32 & 2.76 & 1.78 & 3.01 & 2.23 \\
\hline \multicolumn{7}{|l|}{ Birth order } \\
\hline 1 & 3.21 & 2.82 & 2.58 & 2.19 & 2.37 & 2.00 \\
\hline 2 & 3.22 & 2.63 & 2.16 & 2.36 & 2.27 & 1.83 \\
\hline 3 & 3.56 & 3.38 & 2.46 & 1.88 & 2.51 & 2.17 \\
\hline $4+$ & 4.53 & 4.21 & 2.82 & 2.34 & 3.74 & 2.99 \\
\hline \multicolumn{7}{|l|}{ Marital status } \\
\hline Married & 3.37 & 2.86 & 2.25 & 2.08 & 2.45 & 2.05 \\
\hline Unmarried & 4.69 & 3.80 & 3.41 & 2.65 & 2.39 & 2.00 \\
\hline Cohabiting & - & - & - & - & 2.32 & 1.93 \\
\hline Single & - & - & - & - & 2.41 & 2.27 \\
\hline
\end{tabular}

unmarried. Information on cohabitation was available from 1986, so 'unmarried' was further divided into cohabiting and single. When testing for interaction with period, the six periods were collapsed into three periods: 1967-81, 1982-89, and 1990-93, representing periods with stable rates.

\section{Results}

In the period 1967-93, 2356 SIDS deaths and 4069 postperinatal non-SIDS deaths were ascertained. The SIDS rate was 1.25 in 1967, reached a peak of 2.69 in 1988 and declined to 0.59 in 1993 (fig 1). The non-SIDS rate declined continuously, from 3.79 in 1967 to 1.63 in 1993.

During the study period, the proportion of teenage mothers declined continuously (table 1). The proportion of infants of birth order $4+$ declined from 1967 to 1976 , but remained constant from 1977-81 onwards, and the proportion of unmarried mothers continuously increased in parallel with an increase of cohabiting mothers.

Within each time period, the SIDS rate was negatively associated with maternal age and positively associated with birth order (table 2 ). Infants of unmarried mothers had a higher SIDS rate than infants of married mothers. From 1986 onwards, infants of cohabiting mothers had a similar rate to married mothers, while infants of single mothers had the highest rate.

For non-SIDS deaths, the association with maternal age was $U$ shaped, as was the association with birth order. In the first four time periods, infants of unmarried mothers had a higher rate than infants of married mothers.

SIDS rates were further stratified with regard to maternal age and birth order. Within each birth order category the SIDS rate declined with maternal age, and within each maternal age category the SIDS rate increased with birth order (fig 2). This pattern became clearer with time: the curves became steeper and moved apart (fig 3). Similar curves for non-SIDS deaths (not shown) revealed a different pattern, with much weaker effects of both maternal age and birth order and with no secular trends.

SIDS rates were adjusted for maternal age, birth order, and period in a multivariate model with maternal age, birth order, marital status, and period including interaction terms between period and each of the other factors (table 3). The associations between maternal age and SIDS, and between birth order and SIDS were strengthened. Furthermore, interactions between period and maternal age, and between period and birth order were strong (both $\mathrm{p}$ values for interaction with period $<0.0001)$. The effect of marital status decreased $(\mathrm{p}=0.02)$.

For non-SIDS deaths, there was neither significant interaction between maternal age and period $(p=0.5)$, nor between birth order and period $(p=0.6)$. There was no adverse effect of unmarried motherhood in the last two time periods. 


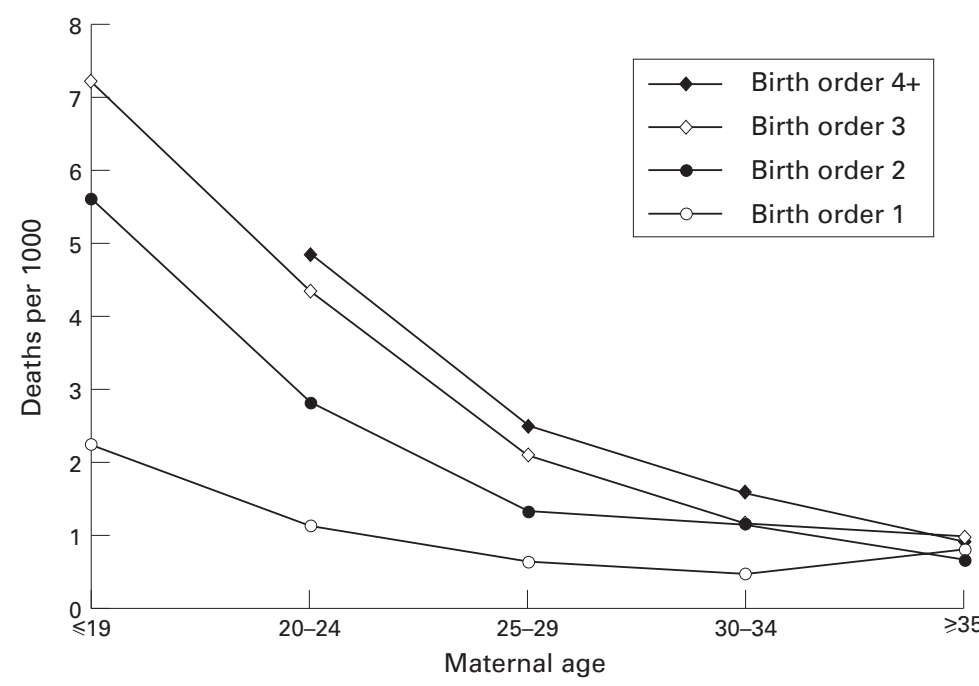

Figure 2 SIDS rates according to maternal age and birth order. Postperinatal deaths, Norway 1967-93. change the risk estimates for infants of young mothers. Alternatively, the maternal age effect might be related to infant care, since young mothers may be less experienced. The birth order effect could be related to care environment, since the strain on mother and family increases with increasing number of children; or to socioeconomic status since mothers with low education on average have more children. ${ }^{14}$ Alternatively, since viral infection is associated with SIDS, ${ }^{15}$ infection load from elder siblings might explain the birth order effect.

The meaning of the term 'unmarried mother' has changed, since many couples are cohabiting instead of being married. Those who cohabit in more recent years would in the past have got married. When unmarried mothers are subdivided into cohabiting and single mothers, the increased risk associated with single mother persisted, and even increased in the last time period. Single mothers now are at greater socioeconomic disadvantage than previously.

In Norway, as in many other western countries, there has been a continuous decline in the proportion of teenage mothers. The general educational level in society has increased, especially among young women. Having a child at a young age is not compatible with the demands of education. Thus the increased adverse effect of young maternal age could be a result of selection mechanisms through which young mothers are increasingly socially disadvantaged. Increased mobility and weaker family networks, for example with parents and parents in law, might have caused a less satisfactory social situation for young mothers. Poorer family networks might also apply to families with a high burden of care, such as those with many children. Society has become more urbanised, more children attend day care and social activities with other children, and the infection load in families with older siblings may have increased. ${ }^{16}$ Over time, these factors may have contributed to the increased effect of high birth order in SIDS. through low birthweight in the infant. However, adjustment for birthweight did not

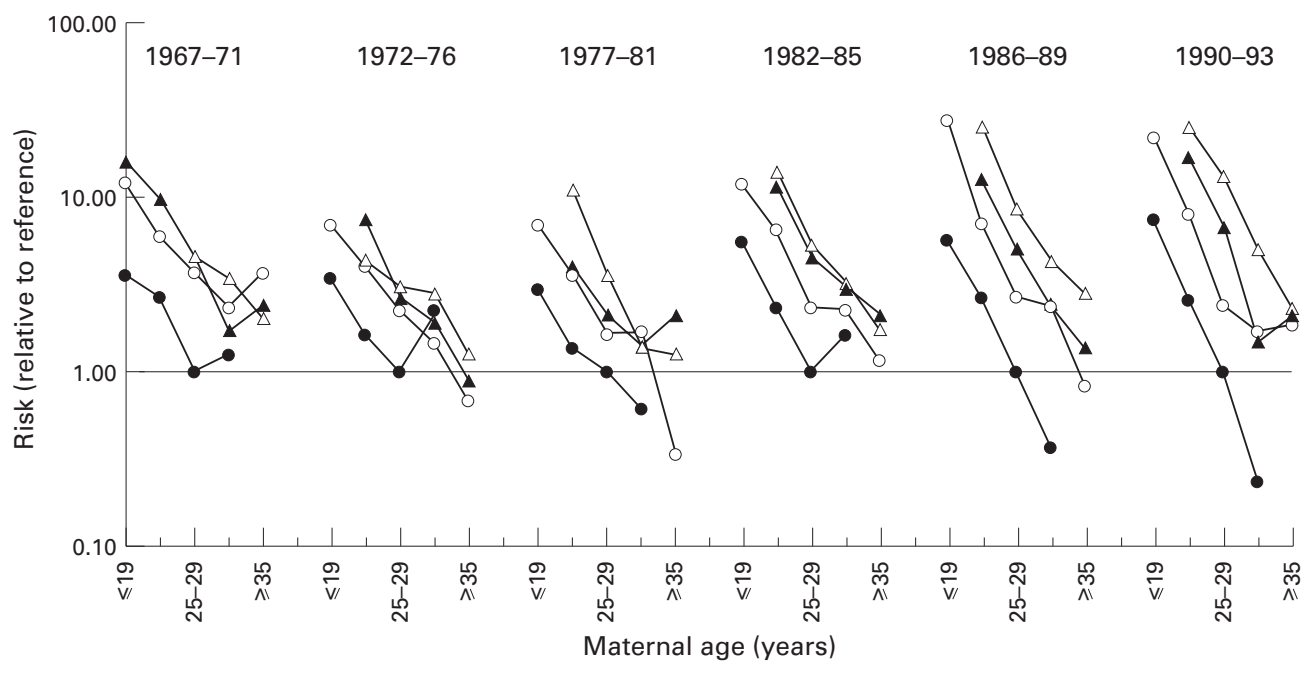

- Birth order $1 \multimap-$ Birth order $2 \multimap$ Birth order $3 \multimap \Delta$ Birth order 4+

Figure 3 Risk for SIDS according to maternal age and birth order, by period of birth. Reference category (risk 1.0) is maternal age 25-29 years of age and birth order 1. Postperinatal deaths, Norway 1967-93. 
Table 3 Adjusted odds ratios (OR) and 95\% confidence intervals (CI) for SIDS and non-SIDS deaths according to maternal age, birth order and marital status, by period of birth, and p values for interaction between periods. Postperinatal deaths Norway, 1967-93

\begin{tabular}{|c|c|c|c|c|c|c|c|}
\hline & \multicolumn{6}{|c|}{ Period of birth } & \multirow{3}{*}{$\begin{array}{l}p \text { Values for } \\
\text { interaction wit } \\
\text { period }\end{array}$} \\
\hline & \multicolumn{2}{|c|}{$1967-81$} & \multicolumn{2}{|c|}{$1982-89$} & \multicolumn{2}{|c|}{ 1990-93 } & \\
\hline & OR & $95 \% C I$ & $\overline{O R}$ & $95 \% C I$ & $O R$ & $95 \% C I$ & \\
\hline \multicolumn{8}{|l|}{ SIDS } \\
\hline Maternal age (years) & & & & & & & $<0.0001$ \\
\hline$\leqslant 19$ & 2.54 & 2.04 to 3.17 & 5.22 & 4.06 to 6.73 & 7.03 & 4.17 to 11.9 & \\
\hline $20-24$ & 1.69 & 1.46 to 1.95 & 2.44 & 2.07 to 2.88 & 2.55 & 1.82 to 3.56 & \\
\hline $25-29$ & 1.0 & & 1.0 & & 1.0 & & \\
\hline $30-34$ & 0.70 & 0.57 to 0.86 & 0.71 & 0.58 to 0.88 & 0.40 & 0.26 to 0.63 & \\
\hline$\geqslant 35$ & 0.49 & 0.35 to 0.67 & 0.45 & 0.32 to 0.63 & 0.34 & 0.19 to 0.62 & \\
\hline Birth order & & & & & & & $<0.0001$ \\
\hline 1 & 1.0 & & 1.0 & & 1.0 & & \\
\hline 2 & 2.44 & 2.10 to 2.85 & 2.88 & 2.43 to 3.42 & 3.42 & 2.38 to 4.91 & \\
\hline 3 & 3.04 & 2.50 to 3.69 & 4.75 & 3.83 to 5.90 & 7.60 & 4.90 to 11.8 & \\
\hline $4+$ & 3.21 & 2.48 to 4.15 & 6.45 & 4.77 to 8.71 & 14.40 & 8.31 to 24.9 & \\
\hline Marital status & & & & & & & 0.02 \\
\hline Married & 1.0 & & 1.0 & & 1.0 & & \\
\hline Unmarried & 1.89 & 1.59 to 2.24 & 1.35 & 1.16 to 1.58 & 1.57 & 1.17 to 2.10 & \\
\hline Cohabiting & - & - & $1.11^{\star}$ & 0.88 to 1.41 & 1.23 & 0.89 to 1.71 & \\
\hline Single & - & - & $1.80^{\star}$ & 1.39 to 2.34 & 2.75 & 1.88 to 4.02 & \\
\hline \multicolumn{8}{|l|}{ Non-SIDS } \\
\hline Maternal age (years) & & & & & & & 0.5 \\
\hline$\leqslant 19$ & 1.44 & 1.24 to 1.68 & 1.37 & 1.03 to 1.83 & 1.62 & 1.05 to 2.51 & \\
\hline $20-24$ & 1.18 & 1.06 to 1.30 & 1.28 & 1.09 to 1.51 & 1.20 & 0.93 to 1.53 & \\
\hline $25-29$ & 1.0 & & 1.0 & & 1.0 & & \\
\hline $30-34$ & 0.98 & 0.86 to 1.11 & 1.02 & 0.85 to 1.22 & 1.17 & 0.92 to 1.48 & \\
\hline$\geqslant 35$ & 1.30 & 1.11 to 1.52 & 1.05 & 0.81 to 1.36 & 1.09 & 0.78 to 1.51 & \\
\hline Birth order & & & & & & & 0.6 \\
\hline 1 & 1.0 & & 1.0 & & 1.0 & & \\
\hline 2 & 1.06 & 0.96 to 1.17 & 1.12 & 0.96 to 1.30 & 0.96 & 0.76 to 1.20 & \\
\hline 3 & 1.31 & 1.15 to 1.49 & 1.11 & 0.90 to 1.38 & 1.12 & 0.84 to 1.50 & \\
\hline $4+$ & 1.61 & 1.38 to 1.87 & 1.55 & 1.16 to 2.05 & 1.54 & 1.06 to 2.23 & \\
\hline Marital status & & & & & & & 0.02 \\
\hline Married & 1.0 & & 1.0 & & 1.0 & & \\
\hline Unmarried & 1.31 & 1.16 to 1.49 & 1.07 & 0.92 to 1.25 & 0.97 & 0.79 to 1.19 & \\
\hline Cohabiting & - & - & $0.95^{\star}$ & 0.76 to 1.19 & 0.95 & 0.77 to 1.18 & \\
\hline Single & - & - & $1.01^{\star}$ & 0.75 to 1.36 & 1.06 & 0.75 to 1.50 & \\
\hline
\end{tabular}

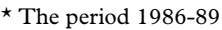

Odds ratios and $p$ values based on the model: $M A+B O+M S+P+M A^{\star} P+B O \star P+M S^{\star} P$

Thus there are indications that the effects on SIDS of variables related to social conditions increased continuously in Norway. During the observed period, social welfare services for families with infants (health care, cash benefits, day care institutions, length of maternity leave) have improved. ${ }^{17}{ }^{18}$ It might have been expected that increasing welfare services available to all should have reduced the effects of social risk factors. On the other hand, the economy has not necessarily produced greater equality. Increasing unemployment is one factor which might have increased group differences. Likewise, the trend towards families having two incomes may have increased the gap between single parent and two parent families, and between families with high and low income. The most important welfare service during infancy - paid maternity leave-is related to maternal employment status, so is most beneficial to those who are employed and have high salaries.

Several studies have shown an association between maternal smoking and SIDS. ${ }^{19}$ Unfortunately, information on smoking habits during pregnancy is not recorded in the medical birth registry. In a Norwegian study, the prevalence of smoking during pregnancy was highest among young women and among women having a later child. ${ }^{20}$ Thus some of the maternal age and birth order effect in SIDS may be explained by smoking habits. In recent years, smoking has become more strongly associated with low socioeconomic status, ${ }^{21}$ possibly contributing to increased effects of young maternal age and high birth order in SIDS.

The sudden decline in the SIDS rate from 1990 onwards correlated with a remarkable decline in the proportion of infants sleeping prone. ${ }^{62}$ We speculate that a higher proportion of young mothers or mothers with many children placed their babies in a non-supine position, thus explaining the secular increase in the effects of maternal age and birth order. However, in the Norwegian study of sleeping position, ${ }^{6}$ we were unable to find an association between young maternal age and prone sleeping, while data on birth order were unavailable (unpublished observations). Sleeping position was not associated with maternal age or birth order among controls in a Nordic SIDS study. ${ }^{23}$ Furthermore, the relative risks associated with young maternal age and increased birth order continued to increase, even after the sudden drop in the SIDS rate. Thus the increased effects of maternal age and birth order are not likely to be explicable by time trends in sleeping position.

We conclude that the effects of young maternal age, high birth order, and single motherhood were much stronger in SIDS than in postperinatal non-SIDS deaths. It has been argued that the concept of SIDS should be abolished as a nosological entity. ${ }^{24}$ In our opinion, the very strong effects in SIDS compared with non-SIDS confirms SIDS as an epidemio- 
logical entity which should be studied from both an aetiological and a preventive point of view. The effects of young maternal age and high birth order on the risk of SIDS became even stronger with time irrespective of the phase of the SIDS epidemic. To an increasing extent, young mothers may represent the socially disadvantaged who smoke more often or have an inadequate social network. To an increasing extent, infants with older siblings may be exposed to infections, contributing to an increased effect of high birth order. The increased differences in SIDS mortality between low and high risk groups suggest that further effort to prevent SIDS should aim particularly at identifying causal mechanisms in high risk groups.

The study was supported by funds from the Research Council of Norway, the Norwegian SIDS Society, and the Bergen Cot Death Research Fund.

1 Peterson DR, vanBelle G, Chinn NM. Sudden infant death syndrome and maternal age. Etiologic implications. $7 A M A$ 1982; 247:2250-2.

2 Irgens LM, Skjærven R. Sudden infant death syndrome and post perinatal mortality in Norwegian birth cohorts 19671980. Acta Paediatr Scand 1986;75:523-9.

3 Kraus JF, Greenland S, Bulterys M. Risk factors for sudden infant death syndrome in the US Collaborative Perinatal infant death syndrome in the US Colla

4 Kraus JF, Franti CE, Borhani NO. Discriminatory risk factors in post-neonatal sudden unexplained death. Am f Epitors in post-neonatal sudde

5 Øyen N, Irgens LM, Skjærven R, Morild I, Markestad T, Rognum TO. Secular trends of sudden infant death syndrome in Norway 1967-1988: application of a method of case identification to Norwegian registry data. Paediatr Perinat Epidemiol 1994;8:263-81.

6 Irgens LM, Markestad T, Baste V, Schreuder P, Skjærven R, Øyen N. Sleeping position and sudden infant death syndrome in Norway 1967-91. Arch Dis Child 1995;72 478-82.

7 Markestad T. Information about sudden infant death syndrome for the general public. Acta Paediatr 1993; 389(suppl): $124-5$.

8 Engelberts AC, de Jonge GA. Choice of sleeping position for infants; possible association with cot death. Arch Dis Child 1990;65:462-7.
9 Mitchell EA, Brunt JM, Everard C. Reduction in mortality from sudden infant death syndrome in New Zealand: 1986-92. Arch Dis Child 1994;70:291-4.

10 Ponsonby AL, Dwyer T, Kasl SV, Cochrane JA, Newman NM. An assessment of the impact of public health activities to reduce the prevalence of the prone sleeping position during infancy: the Tasmanian Cohort Study. Prev Med 1994;23:402-8.

11 Spiers PS, Guntheroth WG. Recommendations to avoid the prone sleeping position and recent statistics for sudden infant death syndrome in the United States. Arch Pediatr Adolesc Med 1994;148:141-6.

12 Gilman EA, Cheng KK, Winter HR, Scragg R. Trends in rates and seasonal distribution of sudden infant deaths in England and Wales, 1988-92. BMF 1995;310:631-2.

13 Dixon WJ, Brown MB, Engelman L, Hill MA, Jennrich RI. $B M D P$ statistical software manual. Berkeley: University of California Press, 1990.

14 Arntzen A, Moum T, Magnus P, Bakketeig LS. The association between maternal education and postneonatal mortality. Trends in Norway, 1968-1991. Int f Epidemiol 1996;25:578-84

15 Gilbert R, Rudd P, Berry PJ, et al. Combined effect of infection and heavy wrapping on the risk of sudden unexpected infant death. Arch Dis Child 1992;67:171-7.

16 Nafstad P, Hagen JA, Botten G, Jaakkola JJK. Lower respiratory tract infections among Norwegian infants with ratory tract infections among Norwegian infants with

17 Nordic Social-Statistical Committee. Social security in the Nordic countries. Scope, expenditure and financing 1978. Stockholm: Nordic Social-Statistical Committee, 1981.

18 Nordic Social-Statistical Committee. Social security in the Nordic countries. Scope, expenditure and financing 1990. Copenhagen: Nordic Social-Statistical Committee, 1993.

19 Haglund B, Cnattingius S. Cigarette smoking as risk factor for sudden infant death syndrome: a population-based study. Am f Public Health 1990;80:29-32.

20 Haug K, Aarø LE, Fugelli P. Smoking habits in early pregnancy and attitudes towards smoking cessation among pregnant women and their partners. Fam Pract 1992;9: 494-9.

21 Statens tobakkskaderåd. Tobakksbruk og holdninger in Norge: utviklingen 1973-95 [in Norwegian]. Oslo: Statens Tobakkskaderåd, 1996.

22 Markestad T, Skadberg B, Hordvik E, Morild I, Irgens LM. Sleeping position and sudden infant death syndrome (SIDS): effect of an intervention programme to avoid prone sleeping. Acta Paediatr 1995;84:375-8.

23 Øyen N, Markestad T, Skjærven R, et al. Combined effects of sleeping position and prenatal risk factors in SIDS. The Nordic Epidemiologic SIDS study. Pediatrics (in press).

24 Huber J. The pathologist's contribution to the prevention of cot death, and why it is important to abolish the concept of SIDS as a nosological entity. In: Rognum TO, ed. Sudden infant death syndrome. New trends in the nineties. Oslo: Scandinavian University Press, 1995:46-9. 